\title{
EXPERIENCING THE "SPIRIT OF PLACE" AS A DESIGN TASK: THE STREET OF HAMRA IN THE HEART OF BEIRUT
}

\author{
Nada El-Khoury ${ }^{\mathrm{a}}$ \\ ${ }^{a}$ Dept. of of Architecture \& Interior Design, School of Architecture \& Design, Lebanese American University, Beirut, \\ Lebanon - nada.elkhoury@lau.edu.lb
}

KEY WORDS: Architecture, Interior Design, Heritage, Spirit of Place, Design Studio

\begin{abstract}
:
The aim of this paper is to introduce a subject related to the concept of re-use of historic places and their contemporary architecture settings. In this research, we examine a particular case study of the street of Hamra, located in the heart of Beirut, Lebanon. Hamra street has a particular character with a specific heritage and local spirit, and it is important to preserve this heritage value as part of any new architectural design intervention. In able to test our intentions of strengthening this strong relation between the specific heritage and any new architectural intervention, we used a method that relies on students' experiments in the case of a design studio. It is an experimental approach where the students of the architecture and design school of the Lebanese American University, were asked as a constraint in their concept, to integrate part of the heritage that characterizes Hamra: "the spirit of place" into their design while using information and communication technologies (ICTs). As a first step, they had to get familiar with the concept of heritage in its general meaning, then they studied the history, the heritage of Hamra and the urban fabric. They had to observe and collect data and then to focus on a main idea that will define the concept of their architectural design. As a second step, results were presented and compared. After analyzing the results, this experimental research showed that it is important to consider the "spirit of place" while designing a space.
\end{abstract}

\section{INTRODUCTION}

The main purpose of the proposed paper is to offer a perspective on the learning and teaching of architectural environment, and the development of a deeper understanding of architecture in the context of a design studio. It presents the results of a number of experiments performed within the context of education dealing with the understanding and interpretation of heritage values. The subject of this research topic is the following: How does one, within the context of a design studio, teach students how to integrate a particular type of heritage in their design?

There is currently a growing consciousness of the importance of this issue not only in Lebanon, but in all countries seeking to conserve their heritage and/or find adaptive re-uses for existing buildings. The current view of the requalification of historic sites and buildings requires a theoretical, conceptual and practical approach, founded on a historical, social and philosophical reflection. For students at the university level, this means developing ideas that are tested and applied through experiential modeling. The pedagogical principles offered prioritize developing knowledge through experimentation and practical work. Such principles are based on a multidisciplinary approach. The students were invited to innovatively reflect on their design project through the perspective of the various conditions defining the "spirit of place". They were required to debate and advance their projects through the various stages of the design: composition, evaluation and communication.

The goal of this presentation can open a new ways and experiences for the interpretation of heritage spaces, using ICTs to encourage the perception of a historic and modern city as a place were sustainable development and heritage are integral parts of the city's character. As demonstrate in a precedent important research the results of this kind of research project have to be used for pedagogical purposes. It is in this direction that we continue our methodological experimentation to contribute to the advancement of knowledge by integrating the expertise of the various disciplines, and where ITCs become a unifying element between these different fields and thereby help to facilitate the process of shared decision making in environmental issues.

The results of this experimental research allow the development of tools geared towards educating youth as to the importance of their urban heritage, while simultaneously teaching them how to integrate sensorial aspects in their design. They can also serve as a basis for initiating other projects dealing with the spatial conception of a site. Heritage education is a key element in the creation of an open heritage environment space and this study of new methods of experimentation will enable us to define and validate new orientations in the way we understand, structure and transfer acquired knowledge about a given architecturally significant complex leading to the development of a "spirit of place" (intangible heritage). This balance can be possible, but there is a need to change the format model of the design process and build a virtual-web-human space to create a new augmented city space.

These reflections have the capacity to pave the way for a reinterpretation of heritage conservation as a dynamic augmented activity based on virtual space and viewing sustainable development as a contribution to the growth of smart cities that consider heritage as a model for sustainable development. This study proposes experimental projects that contribute to the understanding of the role of the heritage aspects of a site in the learning process, whilst integrating themes related to the said heritage identified in the proposal. Those projects are an example of preserving and transmitting information related to the existing heritage and making it available through the proposed projects. Based on these themes, we have selected a location which best meets the proposal's requirements, whilst facilitating an understanding of its heritage. 
The site of which we speak is the district of Hamra. Hamra is located in Beirut (Figure 1) and runs east-west, connecting Beirut central district with the Ras Beirut neighborhoods. Hamra street is one of main streets of the city Beirut. Due to the numerous sidewalk cafes and theatres, Hamra is the center of intellectual activity in Beirut. It is well-known for its restaurants, banks, hotels, shopping areas and amusement centers. Early in 1914-1915, what is know now as Al-Hamra (red in Arabic) was a red soil vine. (Khalaf, Kongstad, 1973) Hamra is for many, the central district of Beirut, it engenders many styles, from traditional to modern to post-modern ones. It unites all people from different ages, different nationalities, different religions, and attract lots of tourists. It is never empty, there's always movement, always people occupying the street. (Figure 2) In considering the case study of Hamra, students have created projects and produced models using digital simulation methods. These models are particularly useful in being able to integrate the specific heritage aspects of a site so as to respond to the demands of the site's architectural and spatial observer. The models presented have a dynamic, interactive character and reflects the spirit of Hamra.

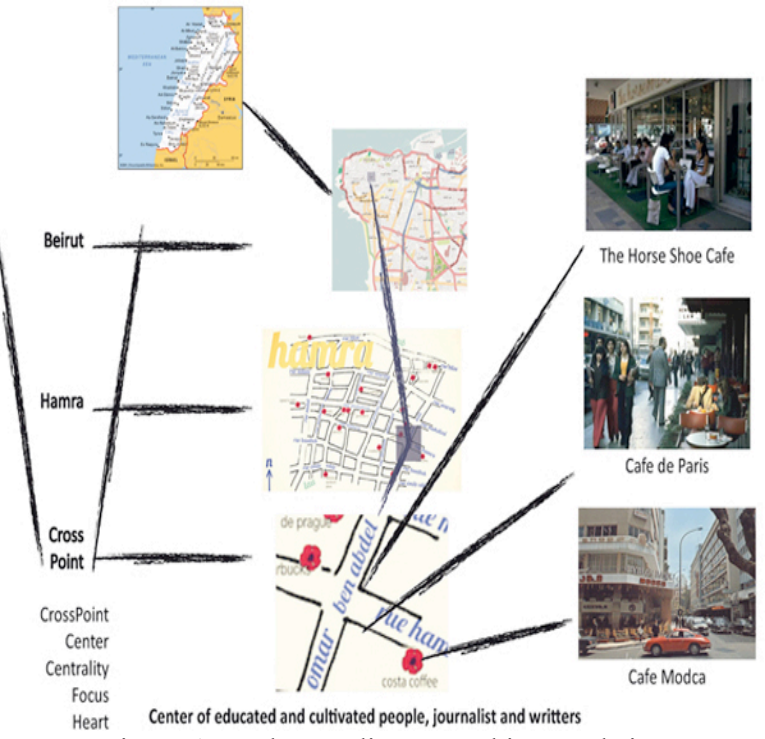

Figure 1. Understanding an architectural site

Our approach allowed us to verify the research hypothesis, which claimed that it is possible to simulate digital models pertaining to the comprehension of a specific architecture so as to allow the student to understand notions of architecture and its history. The results obtained demonstrate that ICT can contribute to the improvement and evolution of the process of understanding an architectural space. These results can serve as a basis for the initiation of other projects dealing with the spatial interpretation of a site, which requires that its architectural and heritage character be better understood. (El-Khoury, 2006; De Paoli, 2002)

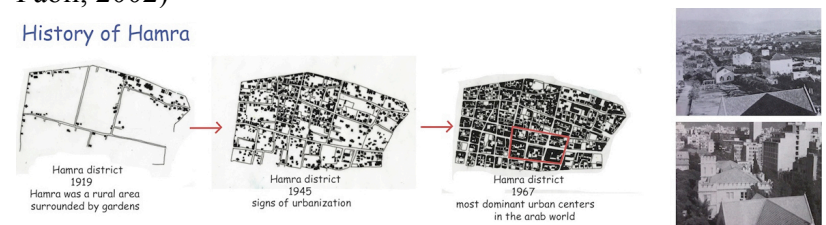

Figure 2. Evolution of the urban fabric in Hamra, (Khalaf, Kongstad, 1973)
Complimenting existing knowledge, this research project contributes not only to the development of the latest comprehensive digital modeling systems, which aid researchers preoccupied with architectural concerns to understand their architectural spaces, but also to the development of new learning tools linked to ICT and the creation of places which facilitate an exchange of knowledge using a multidisciplinary approach. The results of this research project also allow for the development of tools geared towards educating youth on the importance of their heritage whilst simultaneously teaching them how to care for it.

Making use of the latest evolutions computer modeling and new approaches in teaching, this research provides the required knowledge needed to create new systems of architectural management through proposed collaborative work spaces using the new information and communication technologies. It reflects on conditions, methods and challenges discussed in a previous article: Towards using digital modeling systems within the context of e-learning, International, (El-Khoury, De Paoli, 2008)

\section{PRECEDENTS AND TOOLS}

With regard to techniques of representation used to teach and learn architecture, it should be noted that in the twentieth century architecture was illustrated by means of drawings, plans, cross-sections and elevations produced by architects and archaeologists. Three-dimensional reconstructions of spaces were often created as well. Graphic reconstitution in the form of drawings is still widely used today for the expression of architecture. The restoration of ancient monuments is another way in which architectural heritage can be expressed. (Gillot, 2006) In this chronology of architecture expression, (from drawings, to restoration, to life-size reconstruction and scale models), the use of digital modeling systems through virtual spaces, becomes relevant. ICTs allow for an exploration involving the simultaneous use of simulation and experimentation, while respecting the integrity of an architectural space.

During our work we have discovered that the roles of these new technologies are not limited to simple communication and representational tools. Information technologies progressively transform the methodologies adopted for information management in the fields of architecture and particularly influence the development of learning methods dedicated to the teaching of the history of architecture and its role in the design process to architectural design students. Digital 3D models are not often designed to be used in learning environments. However, we aim to illustrate through this paper that it is possible to involve digital models in the teaching of architecture and design. (Figure 3)
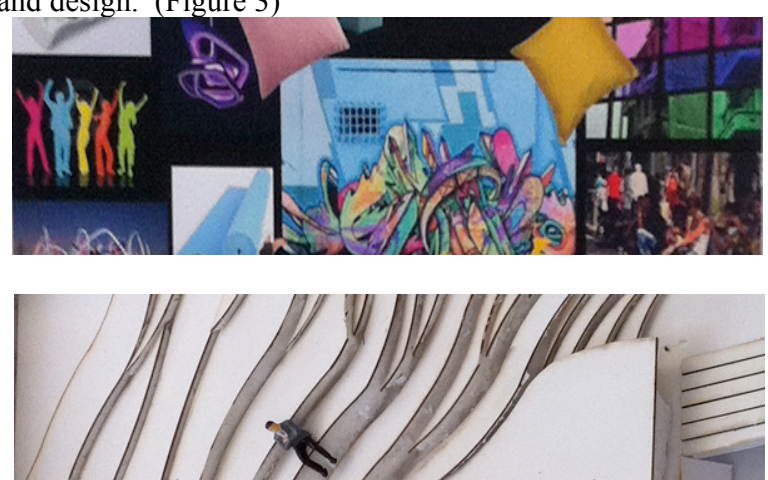

Figure 3. Reflecting the "Spirit of a Place and model production 
Each learning method uses a different approach to accomplish a teaching task whose purpose, in this case, is to bridge the gap between past and present. According to researchers, communication is the process of transferring information from a sender to a receiver through a medium of transmission. Communication, according to Kalay (2004), is also the ability to share information between humans and computers. It is a process that relies on shared knowledge between the various actors who interpret information. "It is relatively easy to communicate information from computers to humans, who posses the intelligence needed to understand textual, numerical, graphical, and auditory messages. But it is frustratingly difficult to communicate information from humans to computers, who lack the intelligence and the ability to interpret messages, unless they are coded in a completely unambiguous manner." (Kalay, 2004)

In fact, research has shown that students encounter difficulties in understanding the sequence and the overlapping of events over the course of a site's history when using traditional learning methods. Rather than finding traditional ways of communicating the past, which is often hard for students to memorize, we propose a means whereby the students can be integrated with, and part of, this past. Students would deal with new experiments that would enable the definition and validation of new methodologies whereby acquired knowledge about a given complex of monuments is understood, structured and transferred.

New research fields concerning teaching theories tend to involve students in the creation of learning tools. Teachers and learners behave as a team while constructing a learning content. In fact, this process is being developed and analyzed by many researchers, such as Jonassen (2001) for instance. His theories meet our need to experience technology as a tool in order to understand the history of architecture by architectural design students.

In identifying the potential of learning theories, an overview is presented which divides them into objective "traditional" and constructive "new" theories. Nowadays, the new theory being used to represent knowledge is constructivism. We will argue in this paper that constructivism, from the perspective of Jonassen (1992), "proposes that since learning is a process of actively constructing knowledge by integrating experiences into the learner's existing schemata, learning environments should support that process by providing multiple perspectives or interpretations of reality and enable knowledge construction in the learner through providing context-rich, experience-based activities." Jonassen describes the applications of technologies as cognitive learning tools rather than as instructional media. $\mathrm{He}$ argues that these tools should be taken from the instructional designers and given to the learners, as tools for knowledge construction rather than as media of conveyance and knowledge acquisition.

Jonassen writes, based on Derry's definition (1990): "Cognitive tools are both mental and computational devices that support, guide, and extend the thinking process of their users". Cognitive tools are not designed to reduce information processing, that is, make a task easier, but to provide an environment that often requires learners to think harder about the subject matter domain being studied. This process generates thoughts that would be impossible without the tool, which is one of cognitive reflection and amplification that helps learners to construct their own realities. Learning is a process in continual construction. The knowledge is in evolution since it is enriched by the experiment of the learner. The environments of training should provide many prospects and possibilities of interpretation of reality and more specifically the interpretation of architectural spaces and historical sites. (Figure 4)
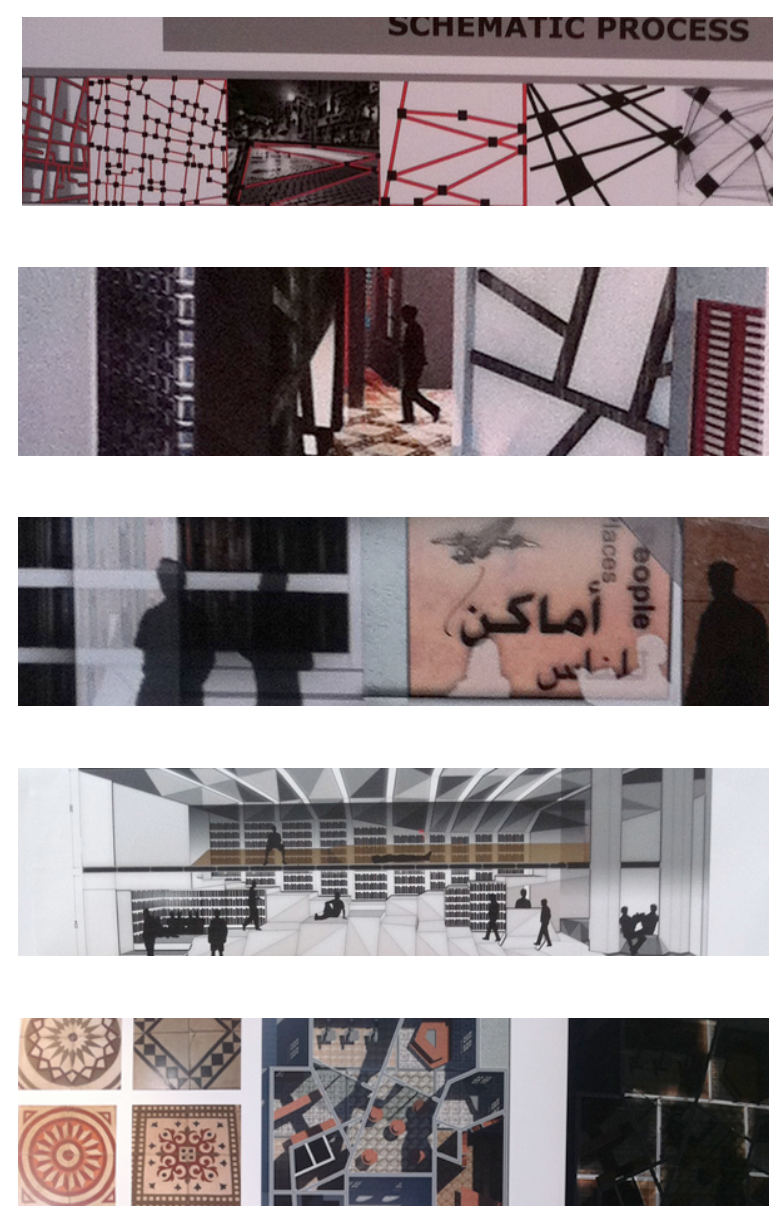

Figure 4. Digital modeling system

\section{DIGITAL MODELLING SYSTEMS AND THE DESIGN PROCESS}

The research project proposed in this paper, has four main goals: (1) to propose to expert users as well as laypeople new ways of understanding architecture and heritage spaces; (2) to find new ways of representing an architectural environment through the reorganisation of the space, based on modern methods that also take into account the heritage of former civilisations; (3) to find a way of developing simple digital programs that facilitate access to information for architecture students regarding different digital methodologies adopted by architects and designers; (4) to take advantage of the digital technologies available nowadays and to integrate them with other approaches proposed to improve the design process of an architectural space.

The learning method proposed is to facilitate the transfer of knowledge and the understanding of architecture by students, using ICT. It typically employs complementary alternatives to traditional teaching methods, such as textbooks and classrooms, by using digital modeling systems based on interactive education techniques together with audio-visual media. Increasing amounts of research have shown that they are also used as information tools during the learning process, thereby allowing the users to take into account a number of different factors during the interpretation of an architectural space. Therefore the research project attempts also to demonstrate that the appropriation of the architectural and heritage aspects of a site is possible during the learning process. 
As a first step, students organized and described approaches for the transfer of knowledge that allow them to exploit representations of spaces with the help of digital modeling software. They then developed the information structure necessary to validate strategies for defining an informative representation model, using software applications that enabled us to create web-based interactive digital devices. Starting with modeling a 3D space of the their projects, they try to tell the story of this space through the ages by adding text data and images. This experiment can display the heritage of a space, the "spirit of a place" showing different layers that illustrate different shapes of the site throughout each stage of its past. So the user can learn by interacting with the digital modeling systems by experiencing friendly interfaces. (Zreik, 2005)

The digital modeling system is used as a window to the past. The activity of comprehension and communication inside this dynamic virtual architectural and historical space is more intuitive and effective than only using abstract technical data for plans and orthogonal views. Furthermore, with the ICT, the students were able to access these digital models remotely. It will also be possible to experience these digital models in an immersive way using projection systems, placing the participant directly into the past whilst respecting the user scale. In addition, sound effects may be added to improve the feeling of presence.

This digital modeling system can also be shared on line within the students' community. Today's networks and new methods of communication favor online collaborations and exchanges and have become the means for representing and communicating the complex relationships between different pieces of information (Horan 2000; Mitchell 1999). By publishing this modeling system, the potential of the virtual dimension is exploited and a cohabitation of virtual models and built spaces is ensured. The virtual dimension of architecture can be considered to be a space for information in constant evolution and a living memory. In addition to the pedagogic benefit, sharing this prototype ensures the active participation of new actors in studying architecture as well as the methods of restoring the man-made environment.

Our new method aims to provide new architectural solutions by technological means, with an emphasis on information gathered on design process in architecture and how to understand it. By using this approach, understanding architecture through its evolution will no longer be seen as a constraint since it can be considered in the very first steps of the design process while using digital tools. During our research we have discovered that the roles of these new technologies are being transformed into those of e-learning tools. Increasing amounts of research has shown that they are also used as information tools during the conception process, thereby allowing the users to take into account a number of different factors during the creation of an architectural space. Therefore the research attempts to demonstrate that the appropriation of the architectural and heritage aspects of a site is possible during the conception process.

Preceded by exploratory research, this study proposes models which contribute to the understanding of the role of the architectural and heritage aspects of a site in the creation process, whilst integrating themes related to the said architecture and heritage identified in the proposal. Students conducted an historical and exploratory research prior to their study; this earlier research introduced a digital design tool that integrates variable aspects of architecture that should be identified throughout the design process of an architectural space.

On the basis of our research results, they propose an initial digital model. This model allows the student to clearly define the design objectives. Then, a final interface is proposed, using digital media tools; it meets the designer's target requirements more adequately. The system provides information for changes in architectural spaces and their consequences. Subsequent research contributes to the development of digital devices that can help the designer in the planning of an architectural space while providing for heritage aspects, but it also contributes to the development of e-learning design tools.

Our research process validates our preliminary hypothesis: "it is possible to simulate digital models pertaining to the comprehension of a specific heritage or "spirit of a place" so as to allow the student to understand notions of architecture and its history."

\section{CONCLUSION}

These reflections pave the way for a new digital approach in architecture and education, in response to the evident challenge of preserving the aspects of a heritage space and the traces of the processes by which the space was built and to take into account regular teaching environments by transforming them into virtual ones with the aid of new information and communication technologies. It is also a contribution to the creation of thought, perception, action and communication processes, an enrichment to global digital memory that will lead students to acquire a better understanding of the relationship between architecture and culture. The project contributes to progress in the area of learning environments by providing avenues for reflection on how to best support and facilitate the interaction between students and the material being learned.

By using digital modeling systems, we also help the development of a dynamic virtual architectural history. In this case the virtual world connects students (present) to the historical site (past). It is not merely a question of proposing experiments to students for communicating a range of information such as that summarized in historical texts, but rather a means of experiencing the building in order to feel the memory of the place (Khayat, 2001). Through this work we explored different avenues to achieving the goals set forth in the research project. Our initial desire to teach architecture and heritage spaces led us to delve further into the concept of elearning. This reflection process enabled us to define the themes for the Hamra district. We reflected on the types of solutions that could be brought to bear. Our conclusion is that research must not lead to the automatic generation of solutions. Rather, its aim is to provide a means of understanding spaces for the improvement of e-learning, using information and communication technologies. The reconstitution of a building facilitates not only their understanding, but also the dialogue between professionals and non-experts. The creation of digital modeling systems provides a new opportunity for teachers, students and the public alike to better understand the tangible and intangible aspects of architectural spaces as well as the history of a site.

The results of this research project could be used for pedagogical purposes. Teaching the history of architectural sites could be made more accessible by means of models to aid in our understanding of these sites. It is in this direction that we continue our experimentation; our aim is also to contribute to the advancement of knowledge by integrating the expertise of the various disciplines involved in e-learning, which can only be enriched as a result. ITCs become a unifying element between these different fields and thereby help to facilitate the process of implementing a collaborative workspace.

enriched as a result. ITCs become a unifying element between these different fields and thereby help to facilitate the process of implementing a collaborative workspace. 


\section{References:}

De Paoli, G., Procedural models and Intelligent Design Assistants in Architecture, dans Computer Graphics and Artificial Intelligence, 3IA, Limoges, 2002

Derry, S. J., Learning strategies for acquiring useful knowledge. In Dimensions of thinking and cognitive instruction, ed. Beau Fly Jones \& Lorna Idol. Erlbaum, Hillsdale, NJ, 1990

El-Khoury, N., De Paoli, G. Dorta, T., « Digital Reconstruction as a means of understanding a building's history - Case studies of a multilayer prototype», dans Proceedings of the 24th Conference on Education and Research in Computer Aided Architectural Design in Europe, Edited by Vassiis Bourdakis and Dimitris Charitos, Volos, Grèce, 2006

El-Khoury, N., De Paoli, G., Towards using digital modeling systems within the context of e-learning, International, Conference on Online Repositories in Architecture, in Browsing Architecture Metadate and Beyond, MACE Consortium, Venise, Italy, published by Fraunhofer IRB verlag, Stuttgart, Germany, 2008

El-Khoury, N., De Paoli, G., « The backstage of Byblos' Roman theatre: New Digital Devices using Information and Communications Technology (ICT) », dans The 7th International Sympposyum on Virtual reality, archaeology and Cultural heritage, VAST, M. Ioannides, D. Arnold, F. NIcolucci, K. Mania éditeurs, Chypre, 2006

Gillot, C., « La restitution du patrimoine archéologique bâti, aux moyens des technologies de l'information et de la communication. État de l'art », Rapport de recherche GRCAO, projet CRSH Contribution d'un moyen informatique à la validation d'hypothèses de restitution architecturale dans le domaine du patrimoine bâti ancien, Montréal, 2006

Horan, T., Digital Places : Building Our City of Bits, ULI-the Urban Land Institute, Washington, 2000

Jonnassen,, D. H., Technology as cognitive tools: Learners as designers, http://itech1.coe.uga.edu/itforum/paper1/paper1.html, 2001

Jonnassen, D. H., Constructivism and the technology of instruction : a conversation, edited by Thomas M. Duffy, Lawrence Erlbaum Associates Publishers, Hillsdale, N.J.,1992

Kalay, Y., Architecture's New Media, The MIT Press, Boston, 2004

Khalaf, S., Kongstad, P., Hamra of Beirut : a case of rapid urbanization, Leiden, The Netherlands : Brill, 1973

Khayat, G., Cultural Heritage and Tourism Development Project Urban Conservation Design Studies, Council of Development \& Reconstruction, Republic of Lebanon, Urban Conservation Design Studies, CDR, AAA Atelier des Architectes Associés, Final Preliminary Report, Beyrouth, 2001

Mitchell, W. J., E-topia : Urban life, Jim-but not as we know it, The MIT Press, Cambridge, 1999.

Zreik, K., Reza B., Augmented Heritage : « A Sustainable ICT Challenge ", dans Augmented Heritage, New Era for Architectural Design, Civil Engineering and Urban Planning, Edited by K. Zreik, R. Beheshti, O. Fakouch, Europia, 2005 